\title{
The genetics of antibody response to paratuberculosis in dairy cattle
}

\author{
T. Pritchard, ${ }^{* 1}$ R. Mrode, ${ }^{*}$ M. Coffey, ${ }^{*}$ K. Bond, $\dagger$ and E. Wall ${ }^{*}$ \\ *Scotland's Rural College (SRUC), Edinburgh, EH9 3JG, United Kingdom \\ †National Milk Records plc, Chippenham, SN15 1BN, United Kingdom
}

\section{ABSTRACT}

Genetic parameters were estimated for antibody response to paratuberculosis (Mycobacterium avium ssp. paratuberculosis) using milk ELISA test results, collected and analyzed by National Milk Records, from Holstein Friesian cows on UK dairy farms in their first 3 lactations. Milk ELISA test results were obtained from 2007 to 2012 and combined with milk recording data and pedigree information. The reduced data set edited for the purposes of genetic parameter estimation consisted of 148,054 milk ELISA records from 64,645 lactations in 40,142 cows of 908 sires, recorded in 641 herds. Milk ELISA test results were $\log _{\mathrm{e}}$-transformed and univariate analysis of 3 alternative animal models and equivalent sire models were considered. The most appropriate model included additive genetic and permanent environmental random effects, whereas maternal effects were significant according to likelihood ratio test and Akaike's information criterion but not for Bayesian information criterion. Heritability and repeatability estimates were 0.06 and 0.37 , respectively, for the chosen animal model and its equivalent sire model. A subset of the data including herds with greater than $10 \%$ positive tests gave a slightly higher heritability of 0.08 . Favorable but generally low significant genetic correlations were obtained between antibody response with 305-d milk yield $(-0.16), 305-d$ protein yield $(-0.16), \log _{\mathrm{e}}$-transformed lactation-average somatic cell count (0.15), and the number of mastitis episodes (0.22). Thus, selection on the antibody response to paratuberculosis, should not be detrimental to production or udder health traits. Testing cattle for paratuberculosis is important for its use in control programs and although the heritability of antibody response was low, breeding against the disease might be a good prospect as a preventative measure to assist together with other approaches in an overall control strategy.

Key words: genetic parameters, paratuberculosis, milk ELISA

\footnotetext{
Received November 13, 2016.

Accepted March 18, 2017.

${ }^{1}$ Corresponding author: Tracey.Pritchard@sruc.ac.uk
}

\section{INTRODUCTION}

Paratuberculosis (or Johne's disease), caused by $M y$ cobacterium avium ssp. paratuberculosis (MAP), occurs worldwide and is a fatal chronic enteritis to which grazing ruminants (domesticated and wild) are particularly susceptible. In Europe and North America, it is considered endemic in dairy cattle, with herd prevalence estimates expected to be higher than $50 \%$ (Nielsen and Toft, 2009; Lombard et al., 2013). This can result in great economic losses to the dairy industry (Raizman et al., 2009) due to decreased production, weight loss, greater risk to other health problems, premature culling, reduced slaughter value, and the cost of veterinary expenses and control measures. The disease also compromises animal welfare (CHAWG, 2012), which is important to address in a society that is increasingly concerned about how animals are raised for food production. Potentially, paratuberculosis could risk the reputation of the agri-food sector due to its pathological similarities to Crohn's disease in humans (Sartor, 2005; Groenendaal and Zagmutt, 2008) together with the capability of the organism to persist in the environment and in a small number of cases it has been found to survive pasteurization of milk (Van Brandt et al., 2011), water treatment (Aboagye and Rowe, 2011), and anaerobic digestion (Slana et al., 2011). Although insufficient evidence of a causal link exists between MAP in livestock and Crohn's disease, the UK Food Standards Agency has adopted a precautionary principle, which appeals for strategies to further minimize human exposure to MAP (Rubery, 2001).

As yet, no cure for the disease exists and control strategies are based upon timely detection and culling of infected animals together with good hygiene practices to reduce transmission (Nielsen, 2009). In some countries, voluntary Johne's control programs have been established (Benedictus et al., 2000; Nielsen, 2007; Bartlett and Pearse, 2012); however, diagnosis of MAP can prove difficult due to its long incubation period and the lack of accurate diagnostic tests (Nielsen, 2008). Diagnostic tests for the disease include serum and milk ELISA, fecal bacterial culture and PCR, skin tests, and IFN- $\gamma$ assays. With a range of diagnostic tests and 
statistical methods used from populations of different countries with varying incidence levels, several studies have indicated that antibody test response to MAP infection is heritable, with estimates ranging from 0.03 (van Hulzen et al., 2011) to 0.23 (Küpper et al., 2012). Breeding for disease resistance might be a good candidate as a preventative measure to assist along with other approaches to control paratuberculosis, particularly because vaccination is of limited efficacy and the disease is incurable. Genetic improvement of disease resistance is a slow and long-term process; however, the results are permanent and cumulative. The heritability of Johne's disease susceptibility has been estimated using milk ELISA (Mortensen et al., 2004; Attalla et al., 2010; van Hulzen et al., 2011), slaughtered animals (Koets et al., 2000), blood serum (Gonda et al., 2006; Hinger et al., 2008; Berry et al., 2010), and fecal culture (Gonda et al., 2006; Küpper et al., 2012) from several countries. Country-specific genetic parameter estimation is valuable, as it can be influenced by disease prevalence (van Hulzen et al., 2011; Küpper et al., 2012). The objectives of this study were (1) to estimate genetic parameters for antibody response to MAP in the UK Holstein Friesian population using milk ELISA test results and (2) to determine the genetic association between antibody response to MAP and production, health, and fertility traits.

\section{MATERIALS AND METHODS}

\section{Data Source and Editing}

Testing milk samples for indication of MAP infection in cows is a service available to farmers in the United Kingdom through National Milk Laboratories, a division of National Milk Records, and uses the commercial milk ELISA IDEXX Pourquier Mycobacterium paratuberculosis Screening Antibody Test (Idexx Laboratories Inc., Westbrook, ME; Bartlett and Pearse, 2012). Herds enrolled in the Johne's control program have their milking cows tested every 3 mo during routine herd recording. Milk ELISA test results from a 5-yr period, 2007 to 2012, were obtained from 2,478 UK herds milking cows born in years 1998 to 2010. Milk ELISA test results were combined with milk recording data (production, fertility, health, pedigree) to obtain information for genetic parameter estimation of antibody response to MAP (AR-MAP).

Milk ELISA test results were $\log _{\mathrm{e}}$-transformed, resulting in a histogram approximating a normal distribution. An earlier study performed by Hinger et al. (2008) reported that $\log _{\mathrm{e}}$-transformed ELISA tests resulted in higher heritability and more robust parameter estimates than treating it as a positive/negative binary trait for MAP status. The following edits of the data were used for the analysis: (1) 100\% Holstein Friesian; (2) at least 50 animals per herd with tests and at least 2 positive tests per herd; (3) all animals required sire and dam records; (4) calving ages for lactation 1, 2, and 3 were 18 to 42,30 to 56 , and 42 to 70 mo, respectively; (5) dams were at least 18 mo at first calving; (6) DIM at Johne's antibody testing were 6 to 305 d; (7) milk test was available within $10 \mathrm{~d}$ of milk ELISA test and also between 6 to $305 \mathrm{~d}$; (8) sires with at least 10 daughters and up to the first 200 daughters born in the test data set were selected; and (9) at least 5 animals per milk herd test day. The ELISA tests were categorized as positive if the sample-to-positive control ratio was 0.3 or higher. After editing, the data set consisted of 40,142 cows from 641 herds with 64,645 lactations and 148,054 milk ELISA records (mean $=3.7$ milk ELISA tests/cow). These animals were sired by 908 bulls with records on 4,021 maternal grandsires. The pedigrees of cows were traced up to 6 generations back, resulting in a file containing the relationship of 166,841 animals that was used for both animal and sire models. Table 1 provides a summary of counts for the number of animals, lactations, and tests in the edited data set.

Joint analysis of log-transformed ELISA test was carried out with both test-day and 305-d lactational measures, which were milk weight at milk ELISA test (TDMY), $\log _{\mathrm{e}}$-transformed somatic cell count at test (TDSCC), 305-d milk yield (MY), 305-d protein yield (PY), 305-d fat yield (FY), $\log _{\mathrm{e}}$-transformed lactation average somatic cell count (LSCC), number of mastitis episodes (NMAS), number of lameness episodes (NLAM), calving interval (CaI), days to first service (DFS), nonreturn at $56 \mathrm{~d}$, and number of inseminations. Further editing included (1) minimum 200 DIM during a lactation; 92) animals required at least 6 SCC tests during a lactation for the calculation of LSCC; (3) CaI was between 300 and $600 \mathrm{~d}$; (4) DFS was not less than $20 \mathrm{~d}$ and not later than $200 \mathrm{DIM}$; (5) 10 or more inseminations until conception were grouped as 10 ; and (6) at least 5 animals per herd-year-season of calving where MY records were available. As defined by Pritchard et al. (2013), NMAS and NLAM was a count of the number of unique episodes within 0 to 305 DIM. A summary of the above traits are shown in Table 2 .

Table 1. Summary of animal, lactation, and test counts in edited data set

\begin{tabular}{|c|c|c|}
\hline Lactation & No. of cows & No. of tests \\
\hline 1 & 25,843 & 61,279 \\
\hline 2 & 23,479 & 51,346 \\
\hline 3 & 15,323 & 35,429 \\
\hline Overall & 40,142 (64,645 lactations) & 148,054 \\
\hline
\end{tabular}




\section{Statistical Analysis}

Univariate Analysis. Genetic parameters of ARMAP were estimated for both animal and sire models in ASReml (version Release 2.0; Gilmour et al., 2006). Significance of fixed effects were first tested using SAS (version 9.2; SAS Institute Inc., Cary, NC) to construct models. Model 1 fitted the additive direct and permanent environmental (due to repeated tests and lactations; on average, 3.7 tests per cow) effects of the animal together with the residual error as random effects. The covariates and fixed and random effects for model 1 are shown in equation 1 :

$$
\begin{aligned}
& Y_{i j k l}=\mu+h t d_{i}+\text { birthyr }_{j}+\text { lact }_{k}+\beta_{1} X_{\text {het }}+\beta_{2} X_{\text {rec }} \\
& +\beta_{3} X_{\text {age }}+\beta_{4}\left(X_{\text {age }}\right)^{2}+\beta_{5} X_{\text {dim }}+\beta_{6}\left(X_{\text {dim }}\right)^{2}+\beta_{7} X_{T D M Y} \\
& +\beta_{8} X_{\text {ageDam }}+\text { direct }_{l}+p e_{l}+e_{i j k l},
\end{aligned}
$$

where $\mathrm{Y}_{i j k l}=$ is an observation for AR-MAP; $\mu$ is the overall mean of trait $\mathrm{Y} ; h t d_{i}=$ fixed effect of $i$ th herd test day (effect specific to all cows on the same test days within a herd); birthyr $_{j}=$ fixed effect of the $j$ th year of birth (1998 to 2010); lact $_{k}=$ fixed effect of $k$ th parity number at test $(1,2,3) ; \beta_{1}$ to $\beta_{8}=$ linear and quadratic regression coefficients of dependent variable $Y$ on heterosis $\left(X_{\text {het }}\right)$, recombination $\left(X_{\text {rec }}\right)$, age at calving in months $\left(X_{\text {age }}\right)$, DIM at test $\left(X_{\text {dim }}\right)$, milk yield at test $\left(\mathrm{X}_{T D M Y}\right)$, and age of dam in months $\left(X_{\text {ageDam }}\right)$; direct $_{l}=$ the random effect of animal $l ; p e_{l}=$ the permanent environmental effect of animal $l$; and $e_{i j k l}=$ residual random error term. Heterosis $($ mean $=9.9 \%$ ) and recombination loss $($ mean $=6.7 \%)$, which consid- ered only 2 breeds (Holstein and Friesian), were calculated as shown in equations 2 and 3 (Wall et al., 2005):

$$
\text { heterosis }=\mathrm{P}_{\mathrm{S}}\left(1-\mathrm{P}_{\mathrm{D}}\right)+\mathrm{P}_{\mathrm{D}}\left(1-\mathrm{P}_{\mathrm{S}}\right) \text {, }
$$

and

$$
\text { recombination loss }=\mathrm{P}_{\mathrm{D}}\left(1-\mathrm{P}_{\mathrm{D}}\right)+\mathrm{P}_{\mathrm{S}}\left(1-\mathrm{P}_{\mathrm{S}}\right),[3]
$$

where $P_{S}$ and $P_{D}$ are the proportion of Holstein for the sire and dam, respectively. In the univariate analysis, it is assumed that the residual effects are independently distributed with variance $\sigma_{e}^{2}$, therefore, $\operatorname{var}(e)=\mathbf{I} \sigma_{e}^{2}=R ; \quad \operatorname{var}(a)=\mathbf{A} \sigma_{a}^{2}=G ;$ and $\operatorname{cov}(a, e)=$ $\operatorname{cov}(e, a)=0$, where $\mathbf{A}$ is the numerator relationship matrix. In the univariate analysis, it is assumed that the residual effects are independently distributed with variance $\sigma_{e}^{2}$; therefore, $\operatorname{var}(e)=\mathbf{I} \sigma_{e}^{2}=\mathrm{R} ; \operatorname{var}(a)=\mathbf{A} \sigma_{a}^{2}$ $=\mathrm{G}$ and $\operatorname{cov}(a, e)=\operatorname{cov}(e, a)=0$, where $\mathbf{I}$ is the identity matrix, $\mathbf{A}$ is the numerator relationship matrix, and $\mathbf{G}$ and $\mathbf{R}$ are the (co)variance matrices for additive genetic $(a)$ and residual $(e)$ effects, respectively.

Further models (models 2 and 3 ) tested the additive maternal genetic effect and the genetic covariance between direct and maternal genetic as additional random effects. Significance was determined using a likelihood ratio test (LRT). Models were compared that differed by 1 variance component and the additional effect was considered to have a significant influence when the difference between $-2 \log$ likelihood $(\log \mathrm{L})$ values was greater than the critical value of 2.79 . The test statistic follows a 50:50 mixture of chi-squared distributions

Table 2. Summary of traits used in bivariate analysis with milk ELISA over the first 3 lactations

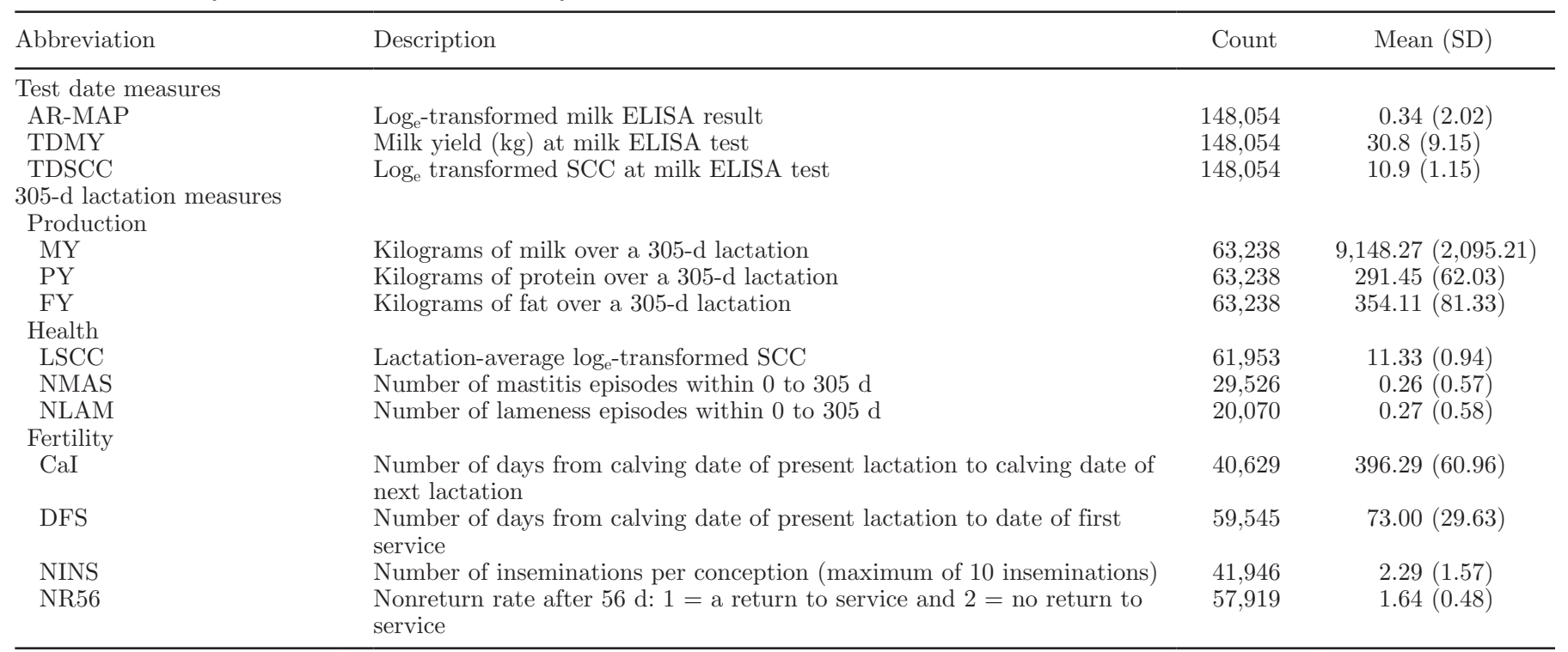


with, respectively, 0 and $1 \mathrm{df}$ with a significance level of 0.05. Whereas increasing the number of parameters may increase the goodness-of-fit, a danger of overparameterization exists (Schwarz, 1978). Therefore, to discourage over-fitting, the choice of model was also judged by Akaike's information criterion (AIC) = $-2 \log \mathrm{L}+2 \mathrm{k}$ (Wada and Kashiwagi, 1990), and the Bayesian information criterion $($ BIC $)=-2 \log \mathrm{L}+$ $\mathrm{k} \ln (\mathrm{n})$ (Schwarz, 1978; Abney et al., 2000), where k = number of independent estimated parameters, and $n$ $=$ total number of observations. The preferred model chosen by AIC and BIC is that with the lowest value. The equivalent sire model to the chosen animal model was also run for comparison of variance components, as it is less computationally demanding. For the sire model, heritability estimates were calculated as 4 times the sire variance component divided by the phenotypic variance. The ratio of permanent environmental variance to total phenotypic variance was calculated as permanent environmental variance minus 3 times the sire variance divided by the phenotypic variance.

Bivariate Analysis. Linear animal models were employed for bivariate analyses between AR-MAP with production, health, and fertility traits. The model for AR-MAP did not include the covariate milk yield at test when analyzed with 305-d production traits due to their high correlation. However, the covariate was included for health and fertility traits. Furthermore, the bivariate model for AR-MAP excluded maternal genetic effects as preliminary results from univariate analysis found these not to be significant components determined by BIC for the animal model. For 305-d production, health, and fertility traits, a single measure was given per lactation in the same lactation that an animal was milk ELISA tested. However, a repeatability model was employed as some animals had milk ELISA tests in more than 1 lactation. The models for test date and 305-d traits are shown by equations 3 and 4, respectively:

$$
\begin{gathered}
Y_{i j k l}=\mu+\text { htd }_{i}+\text { month }_{j}+\text { lact }_{k}+\beta_{1} X_{\text {het }}+\beta_{2} X_{\text {rec }} \\
+\beta_{3} X_{\text {age }}+\beta_{4}\left(X_{\text {age }}\right)^{2}+\beta_{5} X_{\text {dim }}+\beta_{6}\left(X_{\text {dim }}\right)^{2} \\
+ \text { direct }_{l}+\text { pe } \\
+e_{i j k l}
\end{gathered}
$$

and

$$
\begin{aligned}
Y_{i j k l} & =\mu+\text { hys }_{i}+\text { month }_{j}+\text { lact }_{k}+\beta_{1} X_{\text {het }}+\beta_{2} X_{\text {rec }} \\
& +\beta_{3} X_{\text {age }}+\beta_{4}\left(X_{\text {age }}\right)^{2}+\text { direct }_{l}+\text { pe } \\
& +e_{i j k l},
\end{aligned}
$$

where $\mathrm{Y}_{i j k l}=$ is an observation for production, health or fertility; $\mu$ is the overall mean of trait $Y ;$ hys $_{i}=$ fixed effect of $i$ th herd-by-year-by-season (4 seasons per year) of calving; $h t d_{i}=$ fixed effect of $i$ th herd-testdate; month $_{j}=$ fixed effect of the $j$ th month of calving $(12 \mathrm{mo}) ;$ lact $_{k}=$ fixed effect of the $k$ th lactation (3 lactations); $\beta_{1}$ to $\beta_{6}=$ linear and quadratic regression coefficients of dependent variable $Y$ on heterosis $\left(X_{\text {het }}\right)$, recombination $\left(X_{\text {rec }}\right)$, age at calving $\left(X_{\text {age }}\right)$, and DIM at test $\left(X_{\text {dim }}\right)$; direct $_{l}=$ the random effect of animal $l ; p e_{l}=$ the permanent environmental effect of animal $l$; and $e_{i j k l}$ $=$ residual random error term. All bivariate analyses included the additive genetic, permanent environmental (for repeatability model), and residual variances together with corresponding covariances between both traits. It is assumed in the bivariate analyses shown in equation 6 that

$$
\operatorname{var}=\left(\begin{array}{c}
\mathbf{a}_{1} \\
\mathbf{a}_{2} \\
\mathbf{p e}_{1} \\
\mathbf{p e}_{2} \\
\mathbf{e}_{1} \\
\mathbf{e}_{2}
\end{array}\right)=\left(\begin{array}{cccccc}
\mathbf{A G}_{11} & \mathbf{A G}_{12} & 0 & 0 & 0 & 0 \\
\mathbf{A G}_{21} & \mathbf{A G}_{22} & 0 & 0 & 0 & 0 \\
0 & 0 & \mathbf{P}_{11} & \mathbf{P}_{12} & 0 & 0 \\
0 & 0 & \mathbf{P}_{21} & \mathbf{P}_{22} & 0 & 0 \\
0 & 0 & 0 & 0 & \mathbf{R}_{11} & \mathbf{R}_{12} \\
0 & 0 & 0 & 0 & \mathbf{R}_{21} & \mathbf{R}_{22}
\end{array}\right),[6]
$$

where $\mathbf{a}, \mathbf{p e}$, and $\mathbf{e}$ are vectors of random additive, permanent environment, and residual effects for the traits, respectively, with corresponding covariance matrices $\mathbf{G}, \mathbf{P}$ and $\mathbf{R}$, and $\mathbf{A}$ is the relationship matrix.

Genetic parameters for AR-MAP were also estimated using 3 subsets of the edited data set, where herds were categorized according to the percentage of positive tests in a herd during the time frame of the study. The 3 categories were $\leq 5 \%$ ( 225 herds), $>5$ and $\leq 10 \%$ (271 herds), and $>10 \%$ (145 herds) positive tests.

\section{RESULTS AND DISCUSSION}

\section{Genetic Parameter Estimation}

Variance components, heritability, and repeatability estimates of AR-MAP for the 3 linear animal models with differing random effects are shown in Table 3 . Permanent environmental effect contributed about $25 \%$ to the phenotypic variance, and estimates barely changed with the addition of maternal effects to the model. Similarly, this was the case for additive genetic variance, which had minimal change; it decreased slightly with the addition of maternal effects, but increased with the further addition of the covariance between direct and maternal genetic effects. The addition of each random effect was a significant improvement on the previous model according to the LRT and AIC, indicating that 
Table 3. Variance components and heritability (SE) of antibody response from 3 animal models (models 1 to 3) and a sire model (equivalent to model 1)

\begin{tabular}{|c|c|c|c|c|}
\hline \multirow[b]{2}{*}{ Item $^{1}$} & \multicolumn{3}{|c|}{ Animal } & \multirow{2}{*}{$\frac{\text { Sire }}{\text { Model } 1}$} \\
\hline & Model 1 & Model 2 & Model 3 & \\
\hline$\sigma_{a}^{2}$ & $0.18(0.018)$ & $0.17(0.018)$ & $0.19(0.021)$ & $0.18(0.021)$ \\
\hline$\sigma_{p e}^{2}$ & $0.70(0.016)$ & $0.70(0.017)$ & $0.70(0.017)$ & $0.69(0.020)$ \\
\hline$\sigma_{m}^{2}$ & & $0.01(0.006)$ & $0.01(0.007)$ & \\
\hline$\sigma_{a m}^{2}$ & & & $-0.02(0.010)$ & \\
\hline$\sigma_{e}^{2}$ & $1.96(0.009)$ & $1.96(0.009)$ & $1.96(0.009)$ & $1.96(0.009)$ \\
\hline$\sigma_{p}^{2}$ & $2.84(0.013)$ & $2.84(0.013)$ & $2.84(0.013)$ & $2.83(0.013)$ \\
\hline $\begin{array}{l}\mathrm{h}^{2} \\
\mathrm{pe}^{2} \\
\mathrm{~m}^{2}\end{array}$ & $\begin{array}{l}0.06(0.006) \\
0.25(0.006)\end{array}$ & $\begin{array}{l}0.06(0.006) \\
0.25(0.006) \\
0.003(0.002)\end{array}$ & $\begin{array}{l}0.07(0.007) \\
0.25(0.006) \\
0.00(0.003)\end{array}$ & $\begin{array}{l}0.06(0.007) \\
0.24(0.007)\end{array}$ \\
\hline $\mathrm{R}$ & $0.31(0.003)$ & $0.31(0.004)$ & $0.31(0.005)$ & $0.31(0.003)$ \\
\hline $\log L$ & $-4,738.83$ & $-4,736.97$ & $-4,734.88$ & $-4,798.58$ \\
\hline LRT & - & 3.72 & 4.18 & - \\
\hline AIC & $9,481.66$ & $9,479.94$ & $9,477.76$ & - \\
\hline $\mathrm{BIC}$ & $9,501.47$ & $9,509.66$ & $9,517.38$ & - \\
\hline
\end{tabular}

model 3 was the most suitable. However, determined by BIC, we found that model 1 was the most suitable, which included the additive direct effect and the permanent environmental effect of the animal. All models gave very similar results, with heritability estimates ranging from 0.06 to 0.07 and a repeatability estimate of 0.31 , and any of these models could potentially be used depending upon the criteria used.

Sire models had similar results to the animal model, with heritability estimates also ranging from 0.06 to 0.07 and repeatability estimates ranging from 0.30 to 0.31 . The similarities between the results from animal and sire models confirm that the computationally lessdemanding sire model can be employed if the interest is solely for bull selection (i.e., runtime for model 2 was $3 \mathrm{~h}$ vs. $10 \mathrm{~min}$ for the animal model and equivalent sire model, respectively). The results from Hinger et al. (2008) were also virtually the same between sire and animal models $(\sim 0.10)$, whereas Mortensen et al. (2004) found results were slightly higher with the animal model (animal model $=0.10$, sire model $=0.09$ ), with both studies using milk ELISA data; Küpper et al. (2012), however, found higher estimates with the sire model, where animals were tested by fecal culture. The heritability, based upon milk ELISA test results, provides information about the genetic ability to produce antibodies against paratuberculosis. In our study, heritability was low $(\sim 0.06)$ but was in line with other similar studies that used $\log _{\mathrm{e}}$-transformed optical density values from milk ELISA tests in Danish Holstein (Mortensen et al., 2004), German Holstein (Hinger et al., 2008), Dutch Holstein Friesian (van Hulzen et al., 2011), Irish Holstein Friesian (Bermingham et al., 2010), and US Holstein (Attalla et al., 2010), which ranged from 0.03 to 0.10 . Furthermore, it is comparable to other disease traits that are generally low (Bermingham et al., 2010; Pritchard et al., 2013).

Studies differ on whether the trait is measured as continuous or categorized as a binary trait (negative/ positive) or categorical trait. In Israeli Holstein (Shook et al., 2012) and Irish Holstein-Friesian (Berry et al., 2010), ELISA tests from serum were analyzed as a binary trait, which gave heritability estimates of 0.16 and 0.15 , respectively, from a threshold model. Berry et al. (2010) also made the comparison between a threshold and a linear model, as well as analyzing the trait as binary or continuous and obtained lower estimates from the linear model of 0.10 as a binary trait and 0.07 as a continuous trait.

The 3 subsets that represented different herd incidence levels gave similar values to the full data set, with heritability estimates ranging from 0.06 to 0.08 and repeatability estimates ranging from 0.28 to 0.34 (Table 4). The subset including herds with greater than 
Table 4. Variance components and heritability (SE) of antibody response for different herd groupings from an animal model

\begin{tabular}{lccc}
\hline & \multicolumn{3}{c}{ Herd group $^{2}$} \\
\cline { 2 - 4 } Item $^{1}$ & 1 & 2 & 3 \\
\hline$\sigma_{a}^{2}$ & $0.18(0.027)$ & $0.18(0.026)$ & $0.23(0.040)$ \\
$\sigma_{p e}^{2}$ & $1.99(0.015)$ & $1.99(0.013)$ & $1.85(0.017)$ \\
$\sigma_{e}^{2}$ & $0.59(0.026)$ & $0.74(0.025)$ & $0.73(0.038)$ \\
$\sigma_{p}^{2}$ & $2.77(0.020)$ & $2.91(0.020)$ & $2.80(0.028)$ \\
$\mathrm{h}^{2}$ & $0.07(0.010)$ & $0.06(0.009)$ & $0.08(0.014)$ \\
$\mathrm{pe}^{2}$ & $0.21(0.009)$ & $0.25(0.009)$ & $0.26(0.013)$ \\
$\mathrm{R}^{2}$ & $0.28(0.005)$ & $0.32(0.005)$ & $0.34(0.007)$ \\
\hline
\end{tabular}

${ }^{1} \sigma_{a}^{2}=$ direct additive effect; $\sigma_{p e}^{2}=$ permanent environmental variance of animal; $\sigma_{e}^{2}=$ error variance; $\sigma_{p}^{2}=$ phenotypic variance; $\mathrm{pe}^{2}=$ proportion of permanent environmental variance of animal to phenotypic variance; $\mathrm{R}=$ repeatability.

${ }^{2}$ Herd group: $1=$ herds with $\leq 5 \%$ positive tests; $2=$ herds with $>5$ and $\leq 10 \%$ positive tests; $3=$ herds with $>10 \%$ positive tests.

$10 \%$ positive tests, which may imply higher prevalence, gave the largest heritability of 0.084 of all subsets. In Dutch Holstein-Friesian (van Hulzen et al., 2011) and in German Holstein cows (Küpper et al., 2012), higher prevalence also resulted in higher heritability. The repeatability also increased with the percentage increase of positive tests from 0.28 to 0.34 . However, it should be noted that these subsets might not directly explain different prevalence levels and results could be influenced by data structure. In the subset containing herds with the highest percentage of positive tests, the number of tests per cow was higher (4.1 tests) and was lowest (3.4) in the subset containing herds with the least positive tests. Repeatabilities in our study were lower to those reported by Attalla et al. (2010), which ranged from 0.38 to 0.43 . Repeatabilities were found to be higher in herd groups with a higher percentage of positive tests but also had a higher number of tests per cow.

Maternal effects could exist due to intrauterine infection of the fetus, although the risk is considered to be relatively small (Whittington and Windsor, 2009; Adaska and Whitlock, 2012), or the calf could be orally infected by ingesting MAP from the dam soon after birth through colostrum, milk, or feces (Sweeney, 1996; Nielsen et al., 2008). In our study, the contribution of maternal effects to phenotypic variance were small in magnitude $(<1 \%)$, which has been similarly reported in other studies [e.g., $<1 \%$ in the study of Mortensen et al. (2004) and 1.3\% in the study of Attalla et al. (2010) using linear models]. Including maternal effects and the direct-maternal covariance resulted in an improved fit of the model by the LRT and AIC; however, this was not the case as determined by BIC. The data collected in our study is relatively recent and from a short time span. Therefore, it is very unlikely there would be many dam-daughter pairs where both dam and daughter have milk ELISA results. Future analyses with a longer duration of test results could better examine the possible transmission from dam to daughter where both generations have test data available. However, recent farm management changes may have changed the pattern of infection from a very predominant dam-daughter pattern of transmission to cohorts of animals showing up as ELISA-positive. This is due to management practices such as multiple calving in an area and the pooled colostrum effect of 1 infectious cow infecting a whole cohort of calves (Kennedy et al., 2014).

Some caution should be taken in interpreting the trait AR-MAP and its possible use as an indicator trait for selection, as our study did not resolve differences between susceptibility or resistance and an animal's ability to produce a humoral response. However, results from Bermingham et al. (2010) reported a strong positive genetic correlation $(0.84 ; \mathrm{SE}=0.20)$ between serological response to MAP and susceptibility to $M$. avium-purified protein derivative, which suggests that selection for reduced MAP responsiveness may indirectly increase resistance to MAP. It is important, though, to monitor that selection for reduced MAPspecific antibody response does not lead to selection of animals with an impaired humoral response.

\section{Genetic Correlations}

Genetic, permanent environmental, residual, and phenotypic correlations between AR-MAP and production, health, and fertility traits and their heritability estimates are given in Table 5. Genetic correlations between AR-MAP with MY, PY, and udder health traits were significant, whereas TDSCC, FY, NLAM, and fertility traits were not significant. Genetic correlations between NMAS and LSCC with AR-MAP were positive and similar in magnitude (0.15 to 0.22$)$. The genetic correlations between 305-d production traits and TDMY with AR-MAP were all negative and similar in magnitude $(-0.14$ to -0.16$)$.

\section{Production}

The genetic correlation between AR-MAP and 305$\mathrm{d}$ production traits indicate that breeding for animals more resistant to paratuberculosis should not be detrimental to yields of production traits, which supports the results of previous studies (Mortensen et al., 2004; 
Table 5. Estimates of heritability, genetic, permanent environmental, residual, and phenotypic correlations ( \pm SE) from an animal repeatability model between antibody response with production, health and fertility traits across the first 3 lactations

\begin{tabular}{|c|c|c|c|c|c|}
\hline Trait $^{1}$ & Heritability & $\begin{array}{l}\text { Genetic } \\
\text { correlation }\end{array}$ & $\begin{array}{l}\text { Permanent environment } \\
\text { correlation }\end{array}$ & $\begin{array}{l}\text { Residual } \\
\text { correlation }\end{array}$ & $\begin{array}{l}\text { Phenotypic } \\
\text { correlation }\end{array}$ \\
\hline$\overline{T D M Y}$ & $0.13 \pm 0.009$ & $-0.14 \pm 0.062^{*}$ & $-0.13 \pm 0.018$ & $-0.11 \pm 0.003$ & $-0.12 \pm 0.003$ \\
\hline PY & $0.29 \pm 0.014$ & $-0.16 \pm 0.063^{*}$ & $-0.16 \pm 0.023$ & $-0.03 \pm 0.006$ & $0.08 \pm 0.005$ \\
\hline FY & $0.20 \pm 0.014$ & $-0.10 \pm 0.063$ & $-0.14 \pm 0.024$ & $-0.03 \pm 0.006$ & $-0.06 \pm 0.005$ \\
\hline LSCC & $0.10 \pm 0.010$ & $0.15 \pm 0.071^{*}$ & $0.21 \pm 0.026$ & $0.03 \pm 0.005$ & $0.08 \pm 0.004$ \\
\hline $\mathrm{CaI}$ & $0.03 \pm 0.006$ & $-0.11 \pm 0.106$ & $-0.14 \pm 0.073$ & $0.02 \pm 0.006$ & $0.002 \pm 0.005$ \\
\hline DFS & $0.05 \pm 0.007$ & $-0.04 \pm 0.086$ & $-0.06 \pm 0.041$ & $0.01 \pm 0.005$ & $-0.002 \pm 0.004$ \\
\hline NR56 & $0.01 \pm 0.003$ & $-0.02 \pm 0.144$ & $0.24 \pm 0.170$ & $-0.003 \pm 0.005$ & $0.007 \pm 0.004$ \\
\hline NINS & $0.02 \pm 0.005$ & $-0.11 \pm 0.121$ & $-0.07 \pm 0.046$ & $0.018 \pm 0.006$ & $0.004 \pm 0.005$ \\
\hline
\end{tabular}

${ }^{1}$ TDMY $=$ test-date milk weight; TDSCC $=$ test-date $\log _{\mathrm{e}}$-transformed $\mathrm{SCC} ; \mathrm{MY}=305$-d milk yield; PY $=305$ - $\mathrm{d}$ protein yield; FY $=305$-d fat yield; $\mathrm{LSCC}=\log _{\mathrm{e}}$-transformed lactation average SCC; NMAS $=$ number of mastitis episodes; NLAM = number lameness episodes; CaI = calving interval, DFS = days to first service; NR56 = nonreturn at $56 \mathrm{~d}$; NINS $=$ number of inseminations.

*Significant $(P<0.05)$.

Attalla et al., 2010; Berry et al., 2010). Mortensen et al. (2004) reported low and nonsignificant genetic correlations between AR-MAP and daily milk yield $(-0.04)$. Attalla et al. (2010) similarly found a nonsignificant correlation between sire solutions for AR-MAP and predicted transmitting abilities for milk yield, whereas for fat $(-0.20)$ and protein yield $(-0.18)$ correlations were significant and negative, which also suggest selection for these traits would reduce susceptibility to paratuberculosis. From a smaller data set of 4,789 cows, Berry et al. (2010) reported negative and significant genetic correlations between yield traits and AR-MAP as a binary trait, and negative but not different to zero when treated as a continuous trait. However, although with nonsignificant results from another smaller data set of 4,694 cows, Shook et al. (2012) reported positive genetic correlations ranging from 0.15 to 0.22 between MAP and milk yield traits, which suggest that cows with high breeding values for milk yield would be more susceptible to MAP. From another perspective, higher yielders are more likely to succumb to the effects of infection due to the greater lactational stress of high yields, whereas low yielders are more capable of existing with infection. This would be consistent with findings of Norton et al. (2010), where effects of infection were likely to worsen or positive tests were more common when animals were most stressed at calving or at peak milk production. The study of Shook et al. (2012) employed a recursive model that accounted for the effect of MAP infection on yield traits, which might explain the contradictory findings. Several phenotypic association studies also correspond to results from Shook et al. (2012), indicating that cows capable of producing higher yields are more likely to succumb to the disease if infected (Hoogendam et al., 2009; Smith et al., 2009).
The phenotypic correlations in this study were low and positive with MY and PY, but negative with TDMY and FY.

\section{Health}

Few studies exist that have examined genetic associations between AR-MAP and any health traits. A significant positive genetic association was found in our study between AR-MAP and udder health traits, LSCC, and NMAS, which would imply that animals predisposed to higher SCC or mastitis are also predisposed to higher antibody response; thus, breeding against paratuberculosis would, in turn, be favorable by improving udder health. Berry et al. (2010), however, found no significant genetic association between AR-MAP and SCC. However, these results are in line with several nongenetic studies that have found that ELISA-positive cows tend to have higher SCC (McNab et al., 1991; Baptista et al., 2008). Baptista et al. (2008) reported a strong positive phenotypic association, but pointed out that a causal relationship was not apparent between high SCC and AR-MAP. A causality dilemma exists, as it is possible that a cow with MAP infection is more likely to have a higher SCC because of the immune energy expended dealing with MAP or a cow dealing with mastitis is more likely to lose control of her previously controlled MAP infection and become test-positive for MAP. Previous studies have reported positive genetic correlations (i.e., unfavorable) between udder health traits and production (Pritchard et al., 2013); therefore, it is unexpected to have a negative genetic correlation between AR-MAP and production, as a positive genetic correlation exists between the udder health traits and AR-MAP. 


\section{Fertility}

Genetic correlations between AR-MAP and fertility traits were all low, negative, and not significant; therefore, genetic selection to reduce paratuberculosis should not be detrimental to fertility. Berry et al. (2010) also found low nonsignificant negative correlations between AR-MAP and CaI.

\section{CONCLUSIONS}

Testing of cattle for paratuberculosis is important for its use in control programs, and the results of this study show that the same field data could be used to develop breeding tools as part of an overall disease control strategy. This paper presents the first genetic analysis of milk ELISA test results in the United Kingdom, which signify antibody response to MAP, including correlations with other traits in the breeding goal. Despite the low heritability $(<0.10)$ of AR-MAP, potential exists for genetic progress to be made. For instance, there has been a turnaround in the genetic trend of fertility in the United Kingdom almost immediately after the introduction of fertility index in 2005, although the fertility traits included have a heritability of 1 to $4 \%$ (Wall et al., 2003). Genetic improvement might be a long process, but the gains are permanent and cumulative in each generation. In the case of paratuberculosis, vaccination is of limited efficacy at present and the disease is incurable; therefore, genetic improvement is a good candidate as one of the tools for prevention. Selection for resistance to MAP reduces the likelihood of an animal becoming infected when exposed to the pathogen, but also with fewer animals infected it will reduce the number of pathogens in the environment and therefore reduce exposure to the pathogen. Furthermore, genetic correlations with udder health traits were favorable and did not appear detrimental to production traits.

\section{ACKNOWLEDGMENTS}

The authors acknowledge National Milk Records for providing the data. This research was funded by the Scottish Government Rural Affairs and the Environment Portfolio Strategic Research Programme 2011 to 2016 (Environmental Change Programme, Scotland).

\section{REFERENCES}

Abney, M., M. S. McPeek, and C. Ober. 2000. Estimation of variance components of quantitative traits in inbred populations. Am. J. Hum. Genet. 66:629-650.

Aboagye, G., and M. T. Rowe. 2011. Occurrence of Mycobacterium avium ssp. paratuberculosis in raw water and water treatment operations for the production of potable water. Water Res. 45:32713278 .
Adaska, J. M., and R. H. Whitlock. 2012. Low rate of detectable in utero transmission of Mycobacterium avium subspecies paratuberculosis in a dairy herd with a low prevalence of Johne's disease. J. Vet. Diagn. Invest. 24:153-155.

Attalla, S. A., A. J. Seykora, J. B. Cole, and B. J. Heins. 2010. Genetic parameters of milk ELISA scores for Johne's disease. J. Dairy Sci. 93:1729-1735.

Baptista, F. M., S. S. Nielsen, and N. Toft. 2008. Association between the presence of antibodies to Mycobacterium avium subspecies paratuberculosis and somatic cell count. J. Dairy Sci. 91:109-118.

Bartlett, B., and H. L. Pearse. 2012. Integrating milk recording data and disease test results to provide a system for the management of Johne's disease in UK dairy herds. In Proc. ICAR., May 28-June 1, 2012, Cork, Ireland. ICAR, Rome, Italy. Accessed Oct. 25, 2016. http://www.icar.org/wp-content/uploads/2015/09/Bartlett.pdf.

Benedictus, G., J. Verhoeff, Y. H. Schukken, and J. W. Hesselink. 2000. Dutch paratuberculosis programme history, principles and development. Vet. Microbiol. 77:399-413.

Bermingham, M. L., S. J. More, M. Good, A. R. Cromie, P. Mullowney, I. M. Higgins, and D. P. Berry. 2010. Genetic associations between Johne's disease and susceptibility to Mycobacterium bovis and $M y$ cobacterium avium subsp avium in Irish Holstein Friesian dairy cows. Adv. Anim. Biosci. 1:302.

Berry, D. P., M. Good, P. Mullowney, A. R. Cromie, and S. J. More. 2010. Genetic variation in serological response to Mycobacterium avium subspecies paratuberculosis and its association with performance in Irish Holstein-Friesian dairy cows. Livest. Sci. 131:102107.

CHAWG (Cattle Health and Welfare Group). 2012. First annual report: GB cattle health and welfare group. Accessed Jan. 18, 2016. http://www.eblex.org.uk/wp/wp-content/uploads/2013/06/ Cattle-Health-and-Welfare-Report.pdf.

Gilmour, A. R., B. J. Gogel, B. R. Cullis, and R. Thompson. 2006. ASReml User Guide Release 2.0. VSN International Ltd., Hemel Hempstead, UK.

Gonda, M. G., Y. M. Chang, G. E. Shook, M. T. Collins, and B. W. Kirkpatrick. 2006. Genetic variation of Mycobacterium avium ssp. paratuberculosis infection in US Holsteins. J. Dairy Sci. 89:18041812.

Groenendaal, H., and F. J. Zagmutt. 2008. Scenario analysis of changes in consumption of dairy products caused by a hypothetical causal link between Mycobacterium avium subspecies paratuberculosis and Crohn's disease. J. Dairy Sci. 91:3245-3258.

Hinger, M., H. Brandt, and G. Erhardt. 2008. Heritability estimates for antibody response to Mycobacterium avium subspecies paratuberculosis in German Holstein cattle. J. Dairy Sci. 91:3237-3244.

Hoogendam, K., E. Richardson, and J. Mee. 2009. Paratuberculosis sero-status and milk production, SCC and calving interval in Irish dairy herds. Ir. Vet. J. 62:265-271.

Kennedy, A. E., E. F. O'Doherty, N. Byrne, J. O'Mahony, E. M. Kennedy, and R. G. Sayers. 2014. A survey of management practices on Irish dairy farms with emphasis on risk factors for Johne's disease transmission. Ir. Vet. J. 67:27-37.

Koets, A. P., G. Adugna, L. L. Janss, H. J. van Weering, C. H. Kalis, G. H. Wentink, V. P. Rutten, and Y. H. Schukken. 2000. Genetic variation of susceptibility to Mycobacterium avium ssp. paratuberculosis infection in dairy cattle. J. Dairy Sci. 83:2702-2708.

Küpper, J., H. Brandt, K. Donat, and G. Erhardt. 2012. Heritability estimates for Mycobacterium avium subspecies paratuberculosis status of German Holstein cows tested by fecal culture. J. Dairy Sci. 95:2734-2739.

Lombard, J. E., I. A. Gardner, S. R. Jafarzadeh, C. P. Fossler, B. Harris, R. T. Capsel, B. A. Wagner, and W. O. Johnson. 2013. Herd-level prevalence of Mycobacterium avium ssp. paratuberculosis infection in United States dairy herds in 2007. Prev. Vet. Med. 108:234-238.

McNab, W. B., A. H. Meek, S. W. Martin, and J. R. Duncan. 1991. Associations between dairy production indices and lipoarabinomannan enzyme-immunoassay results for paratuberculosis. Can. J. Vet. Res. 55:356-361. 
Mortensen, H., S. S. Nielsen, and P. Berg. 2004. Genetic variation and heritability of the antibody response to Mycobacterium avium subspecies paratuberculosis in Danish Holstein cows. J. Dairy Sci. $87: 2108-2113$

Nielsen, S. S. 2007. Danish control programme for bovine paratuberculosis. Cattle Pract. 15:161-168.

Nielsen, S. S. 2008. Transitions in diagnostic tests used for detection of Mycobacterium avium ssp. paratuberculosis infections in cattle. Vet. Microbiol. 132:274-282.

Nielsen, S. S. 2009. Use of diagnostics for risk-based control of paratuberculosis in dairy herds. In Practice 31:150-154. https://doi. org/10.1136/inpract.31.4.150.

Nielsen, S. S., H. Bjerre, and N. Toft. 2008. Colostrum and milk as risk factors for infection with Mycobacterium avium subspecies paratuberculosis in dairy cattle. J. Dairy Sci. 91:4610-4615.

Nielsen, S. S., and N. Toft. 2009. A review of prevalences of paratuberculosis in farmed animals in Europe. Prev. Vet. Med. 88:1-14.

Norton, S., W. O. Johnson, G. Jones, and C. Heuer. 2010. Evaluation of diagnostic tests for Johne's disease (Mycobacterium avium subspecies paratuberculosis) in New Zealand dairy cows. J. Vet. Diagn. Invest. 22:341-351.

Pritchard, T., M. Coffey, R. Mrode, and E. Wall. 2013. Genetic parameters for production, health, fertility and longevity traits in dairy cows. Animal 7:34-46.

Raizman, E. A., J. P. Fetrow, and S. J. Wells. 2009. Loss of income from cows shedding Mycobacterium avium subspecies paratuberculosis prior to calving compared with cows not shedding the organism on two Minnesota dairy farms. J. Dairy Sci. 92:4929-4936.

Rubery, E. 2001. A review of the evidence for a link between exposure to Mycobacterium paratuberculosis (MAP) and Crohn's Disease (CD) in Humans. Pages 1 to 70 in A Report for the Food Standards Agency. University of Cambridge, Cambridge, UK.

Sartor, R. B. 2005. Does Mycobacterium avium subspecies paratuberculosis cause Crohn's disease? Gut 54:896-898.

Schwarz, G. 1978. Estimating the dimension of a model. Ann. Stat. 6:461-464.
Shook, G. E., M. Chaffer, X. L. Wu, and E. Ezra. 2012. Genetic parameters for paratuberculosis infection and effect of infection on production traits in Israeli Holsteins. Anim. Genet. 43:56-64.

Slana, I., R. Pribylova, A. Kralova, and I. Pavlik. 2011. Persistence of Mycobacterium avium subsp. paratuberculosis at a farm-scale biogas plant supplied with manure from paratuberculosis-affected dairy cattle. Appl. Environ. Microbiol. 77:3115-3119.

Smith, R. L., Y. T. Grohn, A. K. Pradhan, R. H. Whitlock, J. S. Van Kessel, J. M. Smith, D. R. Wolfgang, and Y. H. Schukken. 2009. A longitudinal study for the impact of Johne's disease status on milk production in individual cows. J. Dairy Sci. 92:2653-2661.

Sweeney, R. W. 1996. Transmission of paratuberculosis. Vet. Clin. North Am. Food Anim. Pract. 12:305-312.

Van Brandt, L., I. Van der Plancken, J. De Block, G. Vlaemynck, E. Van Coillie, L. Herman, and M. Hendrickx. 2011. Adequacy of current pasteurization standards to inactivate Mycobacterium paratuberculosis in milk and phosphate buffer. Int. Dairy J. 21:295-304.

van Hulzen. K. J. E., M. Nielen, A. P. Koets, G. de Jong, J. A. M. van Arendonk, and H. C. M. Heuven. 2011. Effect of herd prevalence on heritability estimates of antibody response to Mycobacterium avium subspecies paratuberculosis. J. Dairy Sci. 94:992-997.

Wada, Y., and N. Kashiwagi. 1990. Selecting statistical models with information statistics. J. Dairy Sci. 73:3575-3582.

Wall, E., S. Brotherstone, J. F. Kearney, J. A. Woolliams, and M. P. Coffey. 2005. Impact of nonadditive genetic effects in the estimation of breeding values for fertility and correlated traits. J. Dairy Sci. 88:376-385.

Wall, E., S. Brotherstone, J. A. Woolliams, G. Banos, and M. P. Coffey. 2003. Genetic evaluation of fertility using direct and correlated traits. J. Dairy Sci. 86:4093-4102.

Whittington, R. J., and P. A. Windsor. 2009. In utero infection of cattle with Mycobacterium avium subsp paratuberculosis: A. critical review and meta-analysis. Vet. J. 179:60-69. 